\title{
SOME EXPERIENCES AND SUGGESTIONS ON FORAGE FISH CULTURE
}

\section{Carl L. Hubbs}

\section{Institute for Fisheries Research, University of Michigan}

I think it is hardly necessary to explain to this group the meaning of forage fish; they are, of course, fish that are eaten by larger and more desirable species. The meaning of forage fish has been made known by the work of the United States Bureau of Fisheries, especially through the experiments conducted at the Fairport station; and through the publications of the Bureat and, in some degree, the publications of other institutions and state hatcheries.

The golden shiner is especially suitable for pond fish culture by reason of its breeding habits and its capacity to produce large quantities of small fry throughout the summer in ponds. We have had some experience in Michigan with this species. In experiments carried out for the Department of Conservation at Grand Rapids, Henry Schuil has found it possible in small experimental ponds to produce a very large concentration of golden shiner fry each year. $\mathrm{He}$ has recently reported considerable success in increasing that production through the fertilizing of the ponds. We need a continuation of these experiments so that we can determine in just what manner the largest production of these forage fish can be obtained.

In part of the experiments at Fairport, adult golden shiners were kept with the bass in the ponds and allowed to breed so that as both species spawned, shiner fry were produced upon which the bass fed. This method, according to the word I have had from the superintendents of hatcheries, has proved entirely unsatisfactory at other points. For instance, at the Dwight Lydell hatchery in Michigan the superintendent has informed me that the ponds in which golden shiner adults were kept produced practically no bass, and he is confident that the shiners eat the bass fry after they rise from the beds. Mr. Gill, of the Manchester, Iowa, station of the Bureau of Fisheries, has told me the same story. Apparently at both these places ponds in which there were adult golden shiners produced practically no bass fingerlings. In Texas the experience was the same. Mr. Burr sent me some golden shiners from one of the Texas hatcheries and asked me if I would please identify these minnows for him. He had thought they were golden shiners, but when these minnows were put into a bass pond the bass disappeared, and when he opened the minnows he found the bass there. He had understood that the shiners would not eat the bass fry, therefore what could these fish be? They were golden shiners, just the same. As a result of this and some other observations $I$ think there is grave danger in keeping adult golden shiners in ponds in which the bass are bedding. 
At Fairport that condition was not obtained, which I think is explainable. The Fairport water, pumped out of the Mississippi River, is extremely rich in microscopic life, and the golden shiners there have not eaten the bass fry. That, I think, can be explained by fish nature. Fish nature is very much like human nature: fish are lazy and will not make any more effort than is necessary to attain their ends. If there are plenty of water fleas to be eaten, they are not going to chase an active little bass fry. Furthermore, from the fact that the water was silty there is some question as to the ability of the shiners to see the bass fry clearly enough to chase and catch them. In clear ponds, especially those in which microscopic food life is not exceedingly abundant, I think the evidence is that the golden shiner will eat the bass fry and are dangerous. Moreover, there is competition in such ponds where there is a limited amount of microscopic life on which the earliest stages of bass feed, because the golden shiner feeds extremely heavily upon the water fleas and thus competes with the young bass for feed. As soon, however, as the bass reach a larger size and go about their way seeking larger mouthfuls, as is their custom, they give up this diet of very minute life and eat larger things, at the same time, of course, growing larger. The bass does not have to grow very large in order to be safe from the adult golden shiner, which has a small mouth; so it is perfectly safe, I think, to keep the adult shiners in with the bass after they have reached the No. 1 fingerling stage.

The blunt-nose minnow is another species with which we have had some experience, and it is a very interesting one. This minnow is abundant and widespread throughout almost all of eastern North America, entering almost all sorts of habitats, even living in the warmer trout streams and in lakes and ponds of all sorts. The spawning habits of this creature are a considerable aid to its culture. It has a habit of nesting under any flat object, if necessary scooping out an excavation under such an object so that the eggs are laid in one layer of the under surface of it; and it makes little difference what that flat object is. Along one lake 1 examined something like twenty such flat objects, and all but two had eggs of this species, or of another species with similar habits, underneath. These flat objects might be slabs of wood, flat stones, mussel shells, or even tin cans. The possibilities of production of this minnow were proved by $\mathrm{Mr}$. Schuil in an experiment, in which we cooperated by obtaining adults to stock a quarter acre pond. In the fall 25,000 young of this minnow were obtained-that is production at the rate of 100,000 of these minnows per acre. There were no bass in that pond. Some difficulty was experienced in getting proper slabs for the fish to spawn on. There was probably an insufficient number of slabs, and I think the production could be increased even beyond 100,000 per acre. An interesting device was used in feeding these minnows-a submerged feeding trough 
to which the minnows would go as pigs would to their feeding trough.

At the United States hatchery at Northville, as Mr. Carman, who is here, could tell you better than I, experiments have been run with this species and with the blackhead species, which has similar breeding habits. Apparently very good results in bass production were obtained through the use of this minnow in the ponds. Both species, the blunt-nosed and the blackhead minnow, were used, and a high percentage of the slabs of various sorts which were put into these ponds were utilized by the fish for spawning. On one of the slabs which Mr. Carman lifted out for us we estimated that there were somewhere around 20,000 eggs. Mr. Carman said he would count them; perhaps he can tell you what the count turned out to be. But there was a tremendous quantity of these eggs, apparently some of both species-because there seems to be a slight difference in the size of the egg of these two species, the blackhead having a smaller egg and more commonly laying the eggs not strictly in one layer but more or less in two layers.

There are other species which have similar spawning habits. There are the three kinds of darters, so called, which deposit their eggs similarly on the under side of flat objects. One of these, the Johnny darter, is a fish which will live in ponds and in lakes, utilizing such objects for spawning in quiet water. The fish we call the muddler in Michigan has the same habit. This species, also known to some of you as miller's thumb, is accused of being an enemy of trout through egg eating, but I believe the report which Dr. Greeley gave last year at Baltimore shows that any eggs that would be picked up by such fish are waste eggs anyway. There is a possibility of increasing the forage fish production in trout waters, in ponds and even in trout streams, by inserting flat objects on which they may spawn.

There are certain advantages offered by these two species, the blunt-nosed minnow or the blackhead or fathead minnow, in pond fish culture, especially in smallmouth bass ponds. These fish are not predacious on the fry; their mouths are entirely too small to eat them. They are botton feeders; they eat very little plankton and are therefore less dangerous as competitors than the golden shiner would be. There is one possible disadvantage, and that is the fact that they are egg eaters, clustering about the nests of some fish and eating the eggs in considerable quantities if the adult fish is for some reason driven off the nest. That is a point which needs further study.

There is need for close scientific study of these forage fish, which I can illustrate by speaking of this blunt-nosed minnow, on which we are working. There is the problem of the growth of these fish; if that growth can be increased by providing the proper food for the fish, they will spawn earlier. In Michigan the larger ones spawn early in their second summer, that is, when one year of 
age. I understand in Illinois there is evidence that they spawn even in the year of their birth. If they do that, a tremendous increase in production can be expected. There are probably animals which feed upon the eggs of these minnows. We have noticed at Northville a very large number of empty egg shells without a corresponding number of fish swimming about, suggesting that some enemy is seeking these slabs and feeding upon the eggs of the forage fish. We saw on these slabs such animals as flat worms, leeches and snails. During the past week I have had reason to suspect these flat worms as I watched them feeding upon daphnia in an aquarium. That is something that perhaps we have not suspected, and something that is of considerable importance, probably, in relation to the culture of water fleas. These little flat worms are terrific destroyers of daphnia; they will eat them in large numbers. Apparently the flat worm secretes some mucous in which the daphnia will become entangled in large clusters. You can see the flat worm move definitely toward these sticky masses, from which the daphnia cannot get away. Other animals probably are involved. It is important to determine what sort of animals can eat the eggs of these minnows; it is perfectly obvious that that is necessary if we want to produce minnow fry.

The greatest forage fish in numbers in the Great Lakes region is the lake shiner. This fish occurs in tremendous abundance in the waters of the Great Lakes. During the inshore movements of these fish in the spring and fall they come in in such enormous schools that they actually darken the water. The value of these fish as forage fish for the commercial species of the Great Lakes is considerable. They not only directly feed the fish which are commercially valuable, but they satisfy the fish predators. We determined this in the investigation of tern on Saginaw Bay, where the tern was found to feed almost entirely on this fish. Inasmuch as this fish is so excessively abundant and can be obtained in untold thousands in a few seine hauls, it has been considered as a possible forage fish for introduction into inland lakes to feed the game fish, and also for introduction at the hatcheries to feed the fish which are being reared there. These fish, as I say, are extremely easy to obtain; they are easy to transport; they will live over the winter in the lakes and in the fish ponds, and serve excellently as food for bass, especially when the bass begin feeding in the spring.

At the Dwight Lydell hatchery it was found, however, that these larger adult shiners will eat the bass fry quite easily. We have found another point of interest in this connection, and that is that the lake shiner apparently does not reproduce, at least we have as yet had no evidence that it reproduces, either in the ponds in the hatchery or even in the inland lakes where they have been introduced. Adults will live there and continue to live, but we have no indication that they spawn under such circumstances. 
The gizzard shad is of tremendous importance as a forage fish. It is the most efficient biologically of all the forage fishes. The gizzard shad eats the minute plant life in the water and itself is eaten by the game fish. It is the only species of fish we have which in anything like that degree acts as a single link in the chain between these elementary microscopic plants and the adult fish. In Buckeye Lake here in Ohio there is a tremendous production of game fish, most of which feed upon the gizzard shad; in fact, the gizzard shad is held by the investigators in Ohio to be responsible for the wonderful production of that lake. The same thing holds true for Lake Herrington in Kentucky, which by general reputation is one of the finest bass fishing lakes in the country. It is true also in other lakes and reservoirs in Ohio and Illinois. I think any progran involving forage fish in fishing waters, especially in the reservoirs of the states in this general region, should include consideration of the gizzard shad.

Just a few remarks regarding the importance of this forage fish culture problem. It is quite evident that fingerling production can be increased through forage fish; the work of the United States Bureau of Fisheries at Fairport has, I think, shown that. It is certainly true that ordinarily fish need fish in order that they may grow large. Natural fishing waters can have their fish production increased by an increase in the forage fish in those waters. There is another aspect also, that of providing bait minnows through the rearing of forage fish. This seems to be commercially practicable; when it can be shown that they can be reared at the rate of 100,000 per acre. It seems desirable that fish be reared for sale as minnows since there has been a large depletion of minnows in our natural waters, making it difficult to obtain minnows to fish with. Furthermore, if bait minnows can be reared and sold sufficiently te supply the demand, seines can be outlawed completely and to that extent illegal fishing can be prevented. There are disadvantages involved in this, particularly with regard to goldfish. It is not at all certain that goldfish will not spread and take over our inland lakes. They certainly have spread and become something of a nuisance in Lake Erie, and they may well do so in the inland lakes, so it is a matter that will need watching.

I can only close with one thought, and it is this: I do not believe you would have listened to such a presentation as this ten years ago, at least with any considerable degree of attention. A discussion at that time of what kind of food these tiny minnows in the lakes used and what are their methods of reproduction would have passed as some little playtoy of a college professor. But judging from the amount of correspondence we have had on this subject and from the interest which has been shown in its obvious importance, I think we can say that it is now a live problem, and that what was regarded ten years ago as a scientific playtoy has 
become a matter of practical application. This change in attitude is, I think, a fortunate one which promises much for the future. It is a development that has been made possible by the mutual understanding arrived at between the practical man and the scientific investigator. The practical man has been a little more generous in his attitude toward the work of the scientific man, and the scientific man in fisheries work has come to be willing to tackle problems which are practical in their application.

\section{Discussion}

Mr. Langlors (Ohio): Dr. Hubbs may be interested in knowing that last spring we transferred a batch of adult gizzard shad to one of our largemouth bass rearing ponds, and that they spawned there successfully. The largemouth bass have been feeding on them very successfully this season.

Dr. Bangmam (Ohio): Another thing in favor of the gizzard shad is that they have very few parasites. The lake shiner has a good many that go directly to the bass and some of the other larger lake fish.

Mr. Hogan (Arkansas): With regard to forage fish placed in rearing ponds is it possible that we may get too much fertilizer in for the small minnows? $\Lambda s$ I understand it, daphnia can stand more than the bass. Is it possible that the small minnow fry may be killed by fertilizer?

DR. HUBBs: There might well be a possibility of that, because minnow fry are quite sensitive.

Mr. Hogan: Probably more sensitive than fingerling bass.

DR. HuBss: That is the experience we have had in studies we have made on the effects of certain toxic material on fish life-that bass have withstood the application of chemicals much better than the minnows we have used. I think that is entirely possible. It is just another illustration of the need for investigation of this t:pe of problem.

The President: That has been our experience also, Dr. Hubbs. It is undoubtedly true that the average minnow will not stand anything like as much as the bass. As a matter of fact I do not know of any fresh water fish, with the possible exception of the catish, that will stand as many unfavorable conditions as the black bass.

Dr. Harkness (Ontario, Canada): What is the northern limit of the gizzard shad?

Dr. Hubrs: Georgian Bay, the Great Lakes region. It occurs in Georgian Bay and Saginaw Bay essentially as a sporadic invader; apparently it does not have a permanent residence that far north. It is permanent in Lake Erie.

DR. HARKNESS: In waters north of Lake St. Clair you might not be successful in getting production in bass waters.

DR. HUBBs: There was a big population of gizzard shad in Lake St. Clair and all up through the southern part of Lake Huron and Saginaw Bay this last year. In some years there is a big population there, and in other years there are none. Lake Erie, I believe, is the furthest north where there is a heavy population of gizzard shad. 
Mr. Rodd (Ontario, Canada): What forage minnow would you recommend, Dr. Hubbs, for a lake into which speckled trout have been introduced and which had been barren before the introduction of that species?

Dr. Huabs: A number of species which occur in Canada might be considered. The redbellied dace perhaps would be best if you have a considerable quantity of vegetation. It is quite possible that this miller's thumb, or Cottus, as we call it scientifically, could be used as forage fish. They make fine bait, and certainly are tremendously enjoyed by the trout. I rather think they might be cultivated for that.

MR. RodD: They would not prey on the trout eggs?

Dr. Hubss: They will eat trout eggs, but Dr. Greeley's work indicates that in streams the trout eggs are hidden so far under gravel that any eggs which would be eaten by such little fish would be waste eggs which had floated off anyway and certainly would not reach maturity. I believe this problem of predators on trout eggs is not as serious as formerly it was thought to be. A sucker coming along and picking up a few eggs below a trout nest does not mean that that sucker is having anything to do with the trout production, because the sucker is not going down six or eight or ten inches into the gravel to get at good eggs; he is simply taking waste eggs.

MR. RODD: These lakes I have reference to are fed not by inflowing streams but from higher surrounding hills, probably underground springs or something of that nature. The trout have done extremely well in those waters which were previously barren; the growth in two years is really remarkable.

Dr. Hubrs: Perhaps you had better leave the biological balance alone, if it is good.

MR. RODD: These lakes are owned principally by clubs, who are becoming concemed over the fact that the production of insects is not sufficient to keep up their trout population, and are urging the introduction of a forage minnow. The red bellied dace has been introduced into some of them, with, so far, no detrimental effects.

Dr. Hubss: The northern form of red bellied dace has such an extremely minute mouth that he certainly could not be suspected of eating a trout.

Mr. Rond: Probably there would be less danger from the red bellied dace than from any other fish you have mentioned?

Dr. Hubss: I would think so.

Dr. EMrody (New York) : I want to endorse what Dr. Hubbs has said about the propagation of minnows for sale to fishermen. Certainly it is true that the minnow gatherers are going to exterminate our minnows if something is not done. It is going to be necessary, I think, for us to propagate our own bait fish, and the question is, what fish shall we use for propagation purposes. And then the question of size comes into it, because the fish which will produce most economically will be the one that is produced in ane summer's growth. I have thought about the question a great deal and have tried out a number of species for that purpose, but we never could raise the golden shiner or the blunt-nosed minnow to a large enough size. This year we tried out the chub sucker and also the 
European pearl roach. The chub suckers, at least those we have, will not far outgrow the blunt-nosed minnow, but the European roach, which looks very much like the golden shiner, although it is a silver rather than a golden fish, seems to outgrow anything we have tried out. We have them now of this year's hatch which are three inches long. So far as the numbers produced is concerned, it should exceed anything we have ever tried. Moreover, they spawn all summer long. We have fish in that pond now that are anywhere from one inch to more than three inches long. As a fish to be introduced into a pond with young bass, however, it would not do because it is fully as predatory as the golden shiner; but if the bass could be raised in some adjacent pond and allowed to forage into the pond where the minnows were, it might work all right. That was the principle we had in mind in developing the series of ponds this year; we raised the forage fish in one pond and kept the bass in another, and when the bass reached a certain size we turned them into the minnow pond. The bass had been raised up to that point on daphnia alone, but Mr. Langlois' proposition knocked that all out, so that we are raising bass by feeding them artificial food.

DR. WIEBE: There are several things I would like to say in connection with Dr. Hubbs' paper. In the first place it is undoubtedly a fact that the introduction of the golden shiner at Fairport has not only increased but has multiplied the production of bass fingerlings. I think one reason why it has been so successful there is the extreme turbidity of the water. I made this experiment last year: I put a certain number of bass fry and a certain number of adult shiners in a tank of clear water, and a similar number of shiners and bass fry in a tank of turbid river water. In the course of a few hours the fry in the clear water had all disappeared, and the only cause to which to attribute their disappearance was the shiners. In the turbid water only a relatively small number disappeared during that same period, but apparently it is just a matter of time, for eventually they cleared up the fry.

With reference to the sensitivity of shiners to oxygen, I made a few observations last winter with regard to the oxygen consumption of golden shiners as well as the blunt-nosed minnow, and $I$ find it is considerably higher than that of largemouth black bass. I think it would be far easier to get conditions that would be unfit for the shiner than for the bass. At Fairport we got quite a number of golden shiners that were three inches long, some of them four inches, during the short summer they had to grow.

One difficulty in connection with the blunt-nose and the blackhead that Dr. Hubbs did not point out is with regard to the size of the adults. You have to keep a separate stock outside the bass ponds, because even your larger bass fingerlings will clean up your minnow brood stock, and you have to have a separate pond to keep a supply of brood stock on hand. At Burlington, Iowa, we introduced some gizzard shad, I think at the suggestion of the United States Bureau of Fisheries, and now they are spending money to take them out, filling up big flat boats with them and 
dumping them on the land to get them out of the pond. It does not seem to work out there at all.

Mr. John L. Farley (California) : In California, where trouble was encountered with shiners and it was necessary to get forage fish in a hurry, resource was had to the bluegill sunfish, which proved a very successful forage fish during the summer season. The president can probably tell you more about that than I can, because be is more familiar with it.

The President: We have had a good deal of success with the bluegill sunfish as a forage fish for crappie, but for some reason the results have not been so encouraging when used with bass. I do not know just why it is; we have not really followed it up to any great extent. But we find that when using bluegills with crappie the production of crappie was much greater than without the sunfish, and they also reached a considerably larger size during the summer. In addition to that we got a pretty good production of bluegills, and they also reached a larger size than they do ordinarily, because the crappie kept the numbers of the bluegills down. The greatest trouble with the bluegill is that they reproduce in such large numbers that unless you are very careful your ponds will be overstocked. You will get perhaps two or three bundred thousand bluegills to the acre and they will all be so small that they are not of much account.

Mr. RodD: Has anyone found that the introduction of minnows into a speckled trout lake has had a tendency to make the trout bottom feeders as against surface feeders?

Dr. Greeley (Michigan): I do not think I can answer that directly. I have seen a good many large lakes where there was an abundance both of speckled trout and of minnows. Quite often the speckled trout fishing with the fly is rather difficult in these bodies of water except around the inlets and spring holes, but they do at times get good fly fishing. Cranberry Lake in the Adirondacks produces very many large trout, and the lake is full of minnows; the brook trout range the whole lake and grow to a great size. But only at times is there good fly fishing, and that is always in the inlets and spring holes.

Dr. HusBs: I would like to raise a question as to the advisability of rearing in our waters fish like the pearl roach, European fish of unknown capacities. We should keep in our minds the fact that there is danger in introducing exotic species, especially if there is some native species which reasonably can be expected to take their place.

With regard to the chub sucker, in an experiment we tried in Michigan we got a very fine size-beautiful bait minnow size in the first year, but a rather small production. Out of, if I recall aright, sixty adults in a quarter acre pond, we obtained only three or four hundred fingerling fish, but they were quite sizeable for fishing purposes.

Mr. AlliN (Kentucky): In Lake Herrington in Kentucky, a lake which was first formed some ten years ago, there were very few native fish-that is, game fish such as largemouth and smallmouth and Kentucky bass, and also the crappie. The Kentucky Game and Fish Commission placed in there something like 25,000 bass, and that is all the game fish that had 
been placed in that body of water until last year. Last year we placed in there something like 250,000 of different species of game fish. We found in making a survey there this summer that over 18,000 pounds of bass had been taken out of Lake Herrington in one day. The gizzard shad is the main food of the game fish there. If it were not for the gizzard shad we feel that our supply of bass would fall down very materially.

The President: What is the approximate area of Lake Herrington?

Mr. Allin: It has a shore line of 333 miles. The length from the dam to the backwater is 36 miles. The water at the dam is 286 feet deep. The shore line is very rocky-limestone cliffs on one side, and in some instances on the other shore you have a gradual slope, all the old timber being left there. We tried another scheme on Lake Herrington-the use of floating bass nests-which worked very successfully. The idea was to try to prevent the loss of fish on account of the fluctuations in the water level. We placed thirteen of these nests in this body of water, and a nice brood was produced on each one of them. To show you how much sense fish really have-I have always said that a bass has more sense than ninety per cent of the people who fish for him-ten minutes after this first nest was placed in the water there was a pair of bass on it spawning. With the water temperature at 58 these bass eggs hatched in five and one-half days. Ordinarily it takes seven days in that body of water.

The President: The idea of using floating bass nests is novel, but it strikes me it has great possibilities in reservoirs where there are great fuctuations during the breeding season.

Mr AlLIN: We are working on another project in the form of a floating fish hatchery, which looks as if it is going to help us a good deal in the propagation of bass.

DR. FrELD: With regard to the pearl minnow, I had an opportunity to make some observations on the part it plays in fish culture in Europe, particularly on the Rhone watershed. The pearl minnow is used there as food for the carniviorous fish. It is one of the main crops of fish, and incidentally it serves as food for introduced fish. The pearl roach is one of the five standard fishes in the fish cultural operations in the Rhone watershed. In the younger stages it serves as food for the pickerel and trout the same as our minnows here, but their method is altogether different from ours. They do not go in for unit fish; they make a combination which will work together. They develop the young herbivorous fish which will serve as food for the carnivorous fish, and they like the pearl minnow-poisson blanc-because in their market it is much like our smelt in ours. Notwithstanding this, the pearl minnow in its younger stages serves as food for the more valuable fish. When they are fully grown they are no longer useful as food for fish, but are used as food fior man.

Mr. Lincoln (Michigan): Dr. Hubbs has excused the muddler from eating the trout eggs for the reason that he could not find the eggs. I wonder if he has any experience in determining what percentage of trout fry and small fingerlings the muddler will destroy. 
Dr. HuBbs: I cannot answer that. I have a faint suspicion there would be some loss.

Ma Lincoln: We planted trout fingerlings up to an inch and a half to two inches long in the deep pools where the muddler is found, and we noticed they took the fingerlings up to and including two inches, especially the larger muddlers. 